\title{
TINGKAT PENGETAHUAN IBU MENYUSUI TENTANG PEMBERIAN ASI EKSKLUSIF DI BAGIAN OBSTETRI DAN GINEKOLOGI BLU RSU PROF. DR. R. D. KANDOU MANADO
}

\author{
${ }^{1}$ Vanda Rondonuwu \\ ${ }^{2}$ Maria Loho \\ ${ }^{2}$ Eddy Suparman
}

\author{
${ }^{1}$ Kandidat Skripsi Fakultas Kedokteran Universitas Sam Ratulangi Manado \\ ${ }^{2}$ Bagian Obstetri dan Ginekologi Fakultas Kedokteran Universitas Sam Ratulangi Manado \\ Email: vanda_rondonuwu@yahoo.co.id
}

\begin{abstract}
Breast milk is the best food for infants, it can not be replaced with other foods and no one food that can substitute for breast milk. Breast milk is the one of food types that meet all the needs of infant's elements . The elements include physical, psychological, social, and spiritual. Breast milk contains nutrients, hormones, growth factors elements of immunity, anti-allergic, and antiinflammatory. Methods: This is a descriptive study with cross sectional approach. This study was conducted with samples taken randomly in the postpartum section of Obstetrics Gynecology of Prof. DR. RD Kandou Public Hospital in Manado city. the total numbers of samples is 50 mothers. The data was collected using a questionnaire interview. Results: From the results obtained, based on age less than 20 years of $22 \%, 21-25$ years of $8 \%, 26-30$ years of $28 \%$, 31-35 years of $24 \%$, more than 36 years of $18 \%$. Educational levels of samples are elementary of $8 \%$, junior high school of $18 \%$, senior high school of $62 \%$, and college of $4 \%$. Based on the occupation that working outside home of $32 \%$, while mothers who working in house as much as $22 \%$ and $46 \%$ mothers is a housewife. Based on the level of mothers knowledge towarda exclusive breastfeeding was found and most mothers have a sufficient level of knowledge about exclusive breastfeeding with $62 \%$ rates. Under the provision, we found 22\% Exclusive breastfeeding mothers. Conclusions: It is recommended that mothers should improve their knowledge of exclusive breastfeeding and exclusive breastfeeding attitude, therefore the infants needs can be fullfilled well.
\end{abstract}

Keywords: Knowledge of the mother, Breastfeeding, Exclusive breastfeeding

\begin{abstract}
Abstrak: ASI merupakan makanan terbaik bagi bayi, tidak dapat digantikan dengan makanan lainnya dan tidak ada satupun makanan yang dapat menggantikan ASI. ASI adalah satu jenis makanan yang mencukupi seluruh unsur kebutuhan bayi baik fisik, psikologi, sosial, maupun spiritual. ASI mengandung nutrisi, hormon, unsur kekebalan faktor pertumbuhan, anti alergi, serta anti inflamasi. Metode: Penelitian ini bersifat deskriptif dengan pendekatan cross sectional. Penelitian ini dilakukan dengan pengambilan sampel yang diambil secara acak di ruang nifas bagian Obstetri Ginekologi BLU RSU Prof DR. R.D Kandou Manado, dengan jumlah sampel berjumlah 50 orang. Pengumpulan data dilakukan dengan wawancara menggunakan kuesioner. Hasil: Dari hasil yang didapatkan, berdasarkan umur kurang dari 20 tahun 22\%, 21-25 tahun 8\%, 26-30 tahun 28\%, 31-35 tahun 24\%, lebih dari 36 tahun 18\%. Berdasarkan pendidikan SD 8\%, SLTP 18\%, SLTA 62\%, Akademik/D3 4\%. Berdasarkan pekerjaan yang bekerja diluar rumah 32\%, sedangkan yang bekerja didalam rumah sebanyak 22\% dan tidak bekerja atau IRT 46\%. Berdasarkan tingkat pengetahuan ibu tentang ASI eksklusif didapatkan bahwa paling banyak ibu memiliki tingkat pengetahuan cukup tentang ASI Eksklusif, yakni sebanyak 62\%. Berdasarkan pemberian, didapatkan 22\% ibu memberikan ASI Eksklusif. Simpulan: Disarankan kepada ibu agar lebih meningkatkan pengetahuan tentang ASI Eksklusif dan juga sikap pemberian ASI Eksklusif agar kebutuhan bayi bisa terpenbuhi dengan baik.
\end{abstract}

Kata kunci: Pengetahuan Ibu, Pemberian ASI, ASI Eksklusif 
ASI merupakan makanan terbaik bagi bayi, tidak dapat digantikan dengan makanan lainnya dan tidak ada satupun makanan yang dapat menggantikan ASI. ASI adalah satu jenis makanan yang mencukupi seluruh unsur kebutuhan bayi baik fisik, psikologi, sosial, maupun spiritual. ASI mengandung nutrisi, hormon, unsur kekebalan faktor pertumbuhan, anti alergi, serta anti inflamasi. $^{1}$

Menyusui adalah suatu proses alamiah. Berjuta-juta ibu di seluruh dunia berhasil menyusui bayinya tanpa pernah membaca buku tentang ASI. Bahkan ibu yang buta huruf pun dapat menyusui anaknya dengan baik. Walaupun demikian, dalam lingkungan kebudayaan kita saat ini melakukan hal yang alamiah tidaklah selalu mudah. Seiring dengan perkem-bangannya zaman, terjadi pula peningkatan ilmu pengetahuan dan teknologi yang demikian pesat. Ironinya, pengetahuan lama yang mendasar seperti menyusui justru kadang terlupakan. Dalam penelitian terhadap 900 ibu di sekitar Jabodetabek (1995) diperoleh fakta bahwa yang dapat memberi ASI eksklusif selama 4 bulan hanya sekitar 5\%, padahal 98\% ibu-ibu tersebut menyusui. Dari penelitian tersebut juga didapatkan bahwa 37,9\% dari ibu-ibu tersebut tidak pernah mendaptkan informasi khusus tentang ASI, sedangkan 70,4\% ibu tidak pernah mendengar informasi tentang ASI eksklusif. $^{2}$

Banyak sekali zat gizi yang ada dalam ASI sehingga makanan "ajaib" tersebut tidak boleh dilewatkan. ${ }^{3}$ Air Susu Ibu (ASI), terutama yang ekslusif, tidak tergantikan oleh susu manapun. Bayi yang mendapatkan susu eksklusif akan lebih sehat, lebih cerdas, mempunyai kekebalan terhadap berbagai penyakit dan secara emosional akan lebih nyaman karena kedekatan dengan ibu. Sejumlah penelitian menunjukan bahwa pemberian susu formula dan susu sapi dapat mengakibat-kan alergi bayi. ${ }^{4}$

Pemberian ASI secara eksklusif sampai bayi berusia 4-6 bulan akan menjamin tercapainya pertumbuhan otak secara optimal. Fakta membuktikan angka kematian dan angka terkena penyakit pada bayi penerima ASI eksklusif jauh lebih baik dibandingkan dengan bayi yang tidak mendapat ASI eksklusif. Wajar jika anaknya sehat akan lebih berkembang kepandaiannya daripada anak yang sering sakit, apalagi sakitnya berat. Hasil penelitian terhadap 1000 bayi prematur membuktikan, bayi prematur dengan ASI eksklusif mempunyai IQ lebih tinggi secara bermakna, yaitu 8,3 point lebih tinggi dibandingkan bayi prematur tanpa ASI. Penelitian Riva, dkk menunjukan anak-anak usia 9,5 tahun yang ketika bayi mendapatkan ASI eksklusif memiliki IQ 12,9 point lebih tinggi. ${ }^{5}$

American Academy of Pediatric (1999) kembali menekankan posisinya dalam merekomendasikan pemberian ASI eksklusif sampai paling tidak 1 tahun sebagai bentuk nutrisi bayi terbaik. Institusi ini juga mendukung program yang memungkinkan wanita untuk meneruskan pemberian ASI setelah kembali dari bekerja. Dalam mendukung praktik pemberian ASI, institusi ini melarang iklan susu formula kepada ibu yang memberikan ASI dan distribusi susu formula dalam paket pemulangan tanpa nasihat pemberi asuhan kesehatan. Baby-Friendly Hospital Initiative (BFHI) adalah suatu badan usaha bersama Organisasi Kesehatan Dunia (WHO) dan the United Nations Children's Fund untuk menganjurkan, mempromosi-kan, dan mendukung pemberian ASI sebagai model untuk nutrisi bayi optimal. ${ }^{6}$

Dengan berbagai kelebihan ASI, penggunaan ASI kembali digalakkan agar ASI dapat diberikan sebagai bagian dari upaya untuk menurunkan morbiditas dan mortalitas, sebagai titik awal untuk meningkatkan kualitas sumber daya manusia. $^{7}$

\section{METODE PENELITIAN}

Jenis penelitian yang digunakan yaitu penelitian yang bersifat deskriptif dengan pendekatan cross sectional. Penelitian ini dilakukan di Ruang Nifas BLU RSUP Prof. DR.R.D Kandou Manado pada bulan November 2012. Sampel yang digunakan yaitu sebanyak 50 orang ibu yang di pilih 
Rondonuwu, Loho, Suparman; Tingkat Pengetahuan Ibu Menyusui...

berdasarkan simple random sampling dari ibu-ibu yang dirawat di Ruang Nifas BLU RSUP Prof. DR.R.D Kandou Manado. Pasien yang bersedia ikut serta dalam penelitian menandatangani informed consent, dan mengisi kuesioner yang telah di siapkan. Setelah pengisian kuesioner dilakukan, data yang didapat dicatat dalam lembar kerja peneliti.

\section{HASIL PENELITIAN}

Penelitian yang d Penelitian ini dilakukan dengan pengambilan sampel secara acak di Ruang Rawat Nifas Bagian Obstetri Ginekologi BLU RSU Prof. Dr. R. D. Kandou Manado dan dipilihlah 50 orang untuk menjadi sampel.

Berdasarkan karakteristik responden, penliti membagi menjadi 3 bagian yakni berdasarkan umur, berdasarkan pendidikan serta berdasarkan pekerjaan.

\section{Umur}

Dalam penelitian ini responden yang hamil, sudah melahirkan dan menyusui di ruang rawat nifas berdasarkan umur responden dapat dilihat pada tabel berikut.

Tabel 1. Distribusi Responden berdasarkan Umur di bagian Obstetri dan Ginekologi BLU Prof. R. D. Kandou Malalayang, Manado Tahun 2012.

\begin{tabular}{cccc}
\hline No. & Umur Responden & $\mathbf{N}$ & $\mathbf{\%}$ \\
\hline 1 & $<20$ tahun & 11 & 22 \\
2 & $21-25$ tahun & 4 & 8 \\
3 & $26-30$ tahun & 14 & 28 \\
4 & $31-35$ tahun & 12 & 24 \\
5 & $>36$ tahun & 9 & 18 \\
& total & 50 & 100 \\
\hline
\end{tabular}

Berdasarkan tabel diatas, diperoleh hasil yang menunjukkan bahwa umur 26-30 tahun menjadi umur responden terbanyak dengan jumlah 28\% dari seluruh jumlah responden pada penelitian ini.

\section{Pendidikan}

Dalam penelitian ini responden yang sudah melahirkan dan menyusui di ruang rawat nifas berdasarkan pendidikan responden dapat dilihat pada tabel berikut.

Tabel 2. Distribusi Responden berdasarkan Pendidikan di bagian Obstetri dan Ginekologi BLU Prof. R. D. Kandou Malalayang, Manado Tahun 2012.

\begin{tabular}{llll}
\hline No. & Pendidikan Responden & $\mathbf{N}$ & $\mathbf{\%}$ \\
\hline 1 & SD & 4 & 8 \\
2 & SLTP & 9 & 18 \\
3 & SLTA & 31 & 62 \\
4 & Akademik/D3 & 2 & 4 \\
5 & Perguruan Tinggi & 4 & 8 \\
& Total & 50 & 100 \\
\hline
\end{tabular}

Dari tabel diatas, didapatkan bahwa pendidikan terakhir dari responden yang terbanyak adalah pendidikan SLTA sebanyak 31 orang (62\%).

\section{Pekerjaan}

Dalam penelitian ini responden yang sudah melahirkan dan menyusui di ruang rawat nifas berdasarkan Pekerjaan responden dapat dilihat pada tabel berikut.

Tabel 3. Distribusi Responden berdasarkan Pekerjaan di bagian Obstetri dan Ginekologi BLU RSU Prof. Dr. R. D. Kandou Manado Tahun 2012.

\begin{tabular}{llll}
\hline No. & Pekerjaan Responden & N & \% \\
\hline 1 & Ya, bekerja di luar rumah & 16 & 32 \\
2 & Ya, bekerja di dalam rumah & 11 & 22 \\
3 & tidak bekerja (IRT) & 23 & 46 \\
& Total & 50 & 100 \\
\hline
\end{tabular}


Pada tabel diatas, dapat dilihat bahwa kebanyakan responden tidak bekerja, yaitu sebesar 23 orang (46\%) setelah melahirkan.

Pada penelitian ini digunakan kuisioner untuk menilai seberapa besar pengetahuan ibu tentang ASI eksklusif. Tingkat pengetahuan dinilai berdasarkan skala Guttman dan kemudian dibagi menjadi tiga kategori. Tabel 4 menunjukkan tingkat pengetahuan ibu tentang ASI Eksklusif di bagian Obstetri dan Ginekologi BLU RSU Prof. Dr. R.D Kandou Manado tahun 2012.

Tabel 4. Distribusi Responden berdasarkan Pengetahuan Ibu tentang ASI Eksklusif di bagian Obstetri dan Ginekologi BLU RSU Prof. Dr. R. D. Kandou Manado Tahun 2012.

\begin{tabular}{llll}
\hline No. & Tingkat Pengetahuan & $\mathbf{N}$ & $\mathbf{\%}$ \\
\hline 1 & Kurang (0-5) & 8 & 16 \\
2 & Cukup (6-10) & 31 & 62 \\
3 & Baik (11-15) & 11 & 22 \\
Total & 50 & 100 \\
\hline
\end{tabular}

Dari tabel diatas, dapat dilihat bahwa tingkat pengetahuan ibu terbanyak adalah cukup dengan presentasi sebesar 50\% dengan jumlah responden sebanyak 25 orang. Ibu yang berpengetahuan baik sejumlah 19 orang dengan presentasi 38\%, sedangkan 6 orang responden lainnya berpengetahuan kurang dengan presentasi sebesar12\%.

Untuk melihat pemberian ASI Eksklusif, digunakan kuisioner dengan jumlah 5 pertanyaan. Dalam tabel ini akan Menunjukan berapa banyak dari Responden yang memberikan ASI Eksklusif.

Tabel 5. Distribusi Responden berdasarkan Pemberian ASI Eksklusif di bagian Obstetri dan Ginekologi BLU Prof. R. D. Kandou Manado Tahun 2012.

\begin{tabular}{llll}
\hline No. & Pemberian ASI & N & \% \\
\hline 1 & ASI Eksklusif & 11 & 22 \\
2 & ASI + Susu Formula & 25 & 50 \\
3 & MP-ASI & 14 & 28 \\
Total & 50 & 100 \\
\hline
\end{tabular}

Pada Tabel diatas, dapat dilihat bahwa 25 responden 50\% paling banyak memberikan ASI + Susu Formula.

\section{BAHASAN}

Pada penelitian ini didapatkan 50 sampel yang telah memenuhi kriteria inklusi, yaitu menyusui yang dirawat di ruang nifas.

Berdasarkan hasil penelitian, dapat disimpulkan bahwa sebagian besar ibu-ibu yang dirawat di ruang nifas bagian obstetri dan ginekologi BLU RSU Prof. Dr. R.D. Kandou Manado tahun 2012 berpengetahuan cukup tentang ASI eksklusif. Tingkat pengetahuan ibu tentang ASI eksklusif dapat dipengaruhi oleh berbagai faktor, antara lain lingkungan dan pendidikan.Menurut Hidayat (2005) bahwa pendidikan merupakan penuntun manusia untuk berbuat dan mengisi kehidupan yang dapat digunakan untuk mendapatkan informasi sehingga dapat meningkatkan kualitas hidup. Juga menurut Notoadmodjo (2010) sebagaimana umumnya semakin tinggi pendidikan seseorang semakin mudah mendapatkan informasi dan akhirnya mempengaruhi perilaku seseorang. ${ }^{8}$

Pada penelitian ini juga masih didapatkan ibu yang berpengetahuan kurang tentang ASI eksklusif, yaitu sebesar 16\% dari seluruh jumlah responden. Hal ini diduga disebabkan oleh faktor pendidikan yang relatif masih rendah serta kurangnya penyuluhan yang diberikan dari petugas kesehatan setempat. ${ }^{9}$ Petugas kesehatanpun masih banyak yang tidak memberikan informasi pada saat pemeriksaan kehamilan atau saat memulangkan bayi sehingga ibu kurang tahu tentang ASI eksklusif.

Pada era modern sekarang, ternyata masih menyisakan mitos-mitos negatif tentang menyusui ASI yang dianggap benar. Hal itu menurut Roesli antara lain 1) menyusui akan merubah bentuk payudara ibu, 2) menyusui sulit untuk menurunkan berat badan ibu, 3) ASI tidak cukup pada hari-hari pertama sehingga bayi perlu makanan tambahan, 4) ibu yang bekerja tidak dapat memberikan ASI eksklusif, 5) 
Rondonuwu, Loho, Suparman; Tingkat Pengetahuan Ibu Menyusui...

payudara ibu yang kecil tidak cukup menghasilkan ASI, 6) ASI pertama kali keluar harus dibuang karena kotor, 7) ASI dari ibu kekurangan gizi dan kualitasnya tidak baik. Mitos-mitos tersebut masih melekat karena pengetahuan ibu tentang ASI tidak terlalu baik. ${ }^{4}$

Pemberian ASI Eksklusif yang masih kurang juga didapatkan pada penelitian ini, yaitu 22\% responden. Pemberian ASI Eksklusif yang masih rendah ternyata disebabkan oleh berbagai faktor, salah satunya adalah rendahnya pengetahuan ibu tentang manfaat ASI bagi bayi dan ibu. Selain itu, kurangnya kepedulian dan dukungan suami, keluarga, dan masyarakat untuk memberikan kesempatan kepada ibu untuk menyusui secara eksklusif (Supari, 2006; Kuntari dan Rachmawati, 2006). ${ }^{8}$

Menyusui merupakan hak seorang ibu dan diberi ASI merpakan hak seorang bayi terhadap ibunya tanpa memandang profesi seorang ibu. Giatnya emansipasi wanita saat ini membuat sebagian besar pekerja didominasi oleh para ibu. Seorang ibu tidak bisa menghindari kodratnya sebagai wanita, yaitu hamil, nifas, dan menyusui. namun sekembalinya ibu dari cuti hamil menjadi suatu pilihan yang sulit antara tetap menyusui atau menghentikan pemberian ASI pada bayinya. Lingkungan kerja mempengaruhi keberhasilan menyusui pada ibu bekerja. ${ }^{10}$

Berdasarkan pada berbagai penelitian ilmiah, pemberian ASI Eksklusif dianjurkan selama jangka waktu 6 bulan dengan penjelasan bahwa pada bayi usia kurang dari 6 bulan masih belum mempunyai enzim pencernaan yang sempurna sehingga belum mampu mencerna makanan dengan baik dan hanya ASI yang dapat menjadi makanan pertama dan utama bagi bayi. ${ }^{10}$

\section{SIMPULAN}

Dari penelitian ini bisa dilihat tingkat pengetahuan ibu cukup tentang ASI Eksklusif, tapi didapatkan hanya sedikit yang memberikan ASI Eksklusif sedangkan yang paling banyak adalah yang memberikan ASI + Susu formula.

\section{SARAN}

1. Bagi ibu diharap dapat lebih meningkatkan pengetahuan tentang ASI Eksklusif dan juga sikap pemberian ASI Eksklusif agar kebutuhan bayi bisa terpenuhi dengan baik. Selain ibu juga peran suami dan keluarga sangat pening untuk memberikan dukungan dan perhatian ibu untuk pemberian ASI Eksklusif.

2. Bagi petugas kesehatan, agar dapat lebih giat lagi memberikan penyuluhan tentang ASI Eksklusif kepada ibu hamil dan menyusui.

3. Juga bagi pemerintah, agar dapat lebih menegaskan lagi pelaksaanaan program ASI Eksklusif, terutama di layanan kesehatan milik pemerintah

\section{UCAPAN TERIMA KASIH}

Terima kasih kepada dr. Maria Loho, SpOG-K dan Prof.DR. dr. Eddy Suparman, SpOG-K yang telah memberikan saran serta masukan yang sangat bermanfaat dalam menyelesaikan penelitian ini. Dan juga tak lupa kepada semua pihak yang secara langsung maupun tidak langsung telah menumbuhkan gagasan dalam artikel ini.

\section{DAFTAR PUSTAKA}

1. Hubertin SP. Konsep Penerapan ASI Eksklusif. EGC 5,6

2. Roesli Utami. Mengenal ASI Eksklusif. Vol 1. Jakarta: PT. Niaga Swadaya;2010

3. Yuliarti Nurheti. Keajaiban ASIMakanan Terbaik untuk Kesehatan, Kecerdasan dan Kelincahan si Kecil. Jakarta: C.V ANDI OFFSET;2010

4. Mustofa Ahmad, Hayu Prabandari. Jurnal Studi Gender \& Anak- Pemberian ASI Eksklusif dan Problematika Ibu Menyusui. Jurnal Studi Gender dan Anak Vol.5 No 2 Jul-Des 2010

5. Kasdu Dini. Anak Cerdas. Jakarta: Puspa Sehat;2004

6. Wong DL, Eaton HM, Wilson D, Winkelstein ML, Schwartz P. Wong Buku Ajar Keperawatan Pediatrik.Edisi 6 Volume 1. Jakarta: EGC;2008 
7. Manuaba IBG, Manuaba IAC, Manuaba IBGF. Pengantar Kuliah Obstetri. Jakarta: EGC,2007.

8. Firmansah Nurhuda, Mahmudah. Pengaruh Karakteristik (Pendidikan, Pekerjaan), Pengetahuan dan Sikap Ibu Menyusui Terhadap Pemberian ASI Eksklusif di Kabupaten Tuban. Jurnal Biometrika dan Kependudukan. Vol.1 No 1 Agustus 2012

9. Mahardikha DM, Syamsianah Agustin, Mufnaetty. Hubungan Tingkat Pendidikan dan Pengetahuan Ibu Tentang ASI Dengan
Lama Pemberian ASI Eksklusif Pada Balita Usia 6-24 Bulan di Desa Kebon Agung Kecamatan Kebon Agung Kabupaten Pacitan Provinsi Jawa Timur. Jurnal Unimus. Fakultas Ilmu Keperawatan dan Kesehatan Universitas Muhammadiyah Semarang

10. Setyawati Irni, Sutrisminah Emi. Pentingnya Motivasi dan Persepsi Pimpinan terhadap Perilaku Pemberian ASI Eksklusif pada Ibu bekerja. Jurnal Unissula. Fakultas Ilmu Kesehatan Unissula 